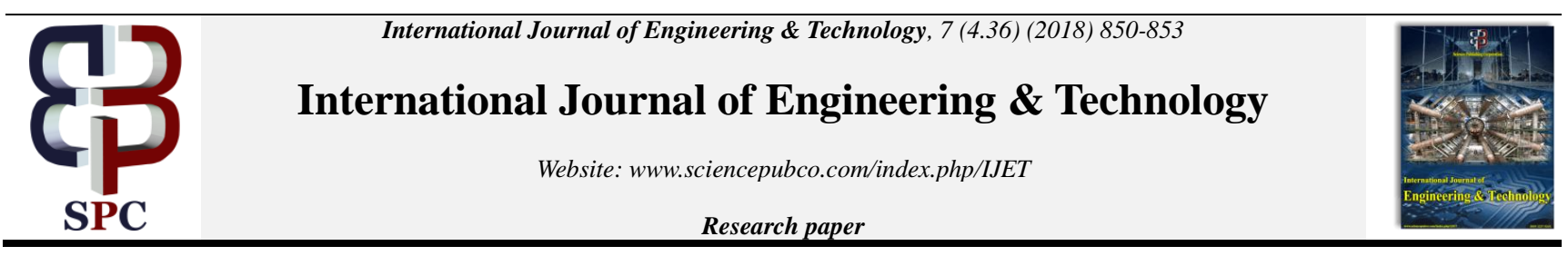

\title{
Negative Marking in Online Sales Portal
}

\author{
K. Palani Raj ${ }^{*}$, G. Veeramani

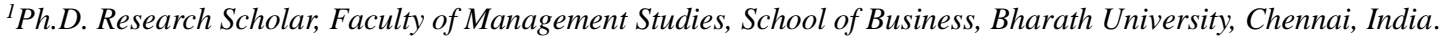 \\ ${ }^{2}$ Professor in Business Administration, Department of Business Administration, Sri Sankara Arts \& Science College, Enathur, \\ Kanchipuram, Tamilnadu, India.
}

\begin{abstract}
Negative marking is provided to the sellers in online portals. It is to avoid unnecessary problems for customers because of sellers in online portal. There are different factors considered for providing negative marking to sellers. Quality of product is improved because of that and it increases the customer satisfaction and hence increases the sales in online portal. There are possibilities for selling defective products and delay in delivery of products in online portal. Since the customers are not contacting the sellers directly, there are more possibilities for such errors. Negative marking plays a vital role in online marketing to help the customers to buy the products with confidence. In this research paper, a deep analysis of negative marking is carried out to understand the effects of negative marking in online sales.

Key words: Negative, Marketing, Online Sales Portal
\end{abstract}

\section{Introduction}

Internet became an important source for marketing. Traditional Marketing methods are outdated. It is must to follow the new marketing trends to sustain in market. Improving the quality of products is important in marketing. There are different types of methodologies carried out by the marketers to improve the sales. One among that is negative marking in online portals.

Retaining the existing customers, improving customer satisfaction and developing new customers is the prospect in marketing.

Recently there is an enormous development in the internet marketing. Most of the companies prefer to advertise through internet. Internet has become and inevitable source for marketers. Selling through online eases the customer buying phenomenon. There are so many advantages for internet sales. It provides enough options for customer to analyze different types of alternatives and to select a choice within their budget.

Negative marking in online portals is a good decision making process in marketing management. Online marketing portals give negative marking for sellers due to various reasons. It restricts or enhances the seller privileges based on the performance. This kind of new approach helps consumers to get a quality product. It makes iteration for selling a good product.

Studies carried out in different online portals were used to understand the process of negative marking in online portals.

\section{Objective of this study}

Objective of this study is to understand the negative marking for sellers in online portals. It includes two topics,

1. Negative marking procedure followed in online portals.

2. Consumer response for negative marking.

\section{Literature review}

There are so many developments in online marketing. So many marketing experts predicted the importance of internet in marketing and how it dominates the current market. Efficient online marketing requires different types of approaches for improving the quality of sales. Negative marking is a modern approach used by the online portals to increase the quality of sales.

Online sales become an important source for marketers. Kotler, P. and Keller, K.L explains that Marketing management is the technology and development of selecting different target markets and accomplishing, retaining customers and improving customers through new concepts, implementing and communicating superior customer value.

The internet has flipped how consumers engage with brands. It is developing the marketing economics and it makes many of the traditional strategies and structures outdated. Doing business in old way became unsustainable to the marketers (Edelman, 2010).

Mickey Kosloski, Sharon R. Davis (2015) explained Retailing and E-tailing. Information provided in that will allow comparing and contrasting a brick and mortar business to the one that is in online. The Authors explained the e-tailing concept in detail.

According to R.Venkatesh (2016) E-commerce is defined as it is the way of conducting different types of business through internet by the companies and customers using electronic transactions. He explains E-marketing is also known as Internet Marketing, Web marketing, and online marketing etc. Development of E Tailing in India, also he explains growth, issues opportunities and development of E Tailing in India.

Riccardo Di Nisio et al. (2010) explained the application of structural equations for understanding the customer satisfaction and customer loyalty measurement (ACSI and ECSI models). This study is helpful for designing and ACSI model adaptation for 
India, since it explores the antecedents of customer satisfaction and customer's reliability.

Neil F. Doherty (2010) explains that Electronic plays an importan intermediate role, one to one marketing is becoming reality, more competitive prices, and actually most important is consumer becoming more powerful.

RE Anderson (1973) proves that, beyond a point, consumers will not accept increasing deviation between the product claims and actual performance, at least for simple relative or for very easily understandable products. During the reach of this threshold rejection, consumers recognize the product is less affirmative and it is considered that, performance is lower than the level of expectations. For complex products, that is more considerable haziness and uncertainty in making judgments, can yield different type of results, and because consumers may be apt for more dependent and expect the clarity of information provided to them. Bernadette Tiernam explains the procedure for incorporating the electronic commerce into new start up businesses and existing business. He is explaining how to design and develop a web site, and how to promote it with advertisement. Process flow order and customer service procedures, maintenance and security. $\mathrm{He}$ also explains the digital middle man concept.

Aleksandrs Lvovs (2011) reveals that, Index of Consumer Dissatisfaction is used for characterizing factor in reliability level. Studies made by Liu, Kang, Bai, and Zhang, (2006) established the relationship between consumer behavior and customer dissatisfaction, and the customers who are not satisfied perhaps making complaint.

Simon Gyasi Nimako (2012) provides the experimental proof for consumer complaining behavior. He also explains if the overall satisfaction is properly managed, previous dissatisfaction may not always make an overall negatively affect.

\section{Negative marking}

Negative marking was given to the customer by considering the percentage. Say for example, Sellers need to maintain a defect rate of $5 \%$ or lower to meet minimum global seller performance standards and a defect rate of $2 \%$ or lower to meet global Top Rated Seller standards. For sellers with defects more than five percent, number of listing is restricted. That means, cannot add more number of new products. Unless supplier resolve the issue, listing restrictions are not withdrawn, sellers need to prove their capability and increase the positive percentage more than $95 \%$, then, restriction for listing is removed.

Table 1: Survey for Negative Marking

Whether Negative marking improves quality of products?

\begin{tabular}{|l|l|l|}
\hline Answer & Yes & No \\
\hline Number of response & 44 & 6 \\
\hline
\end{tabular}

A survey is conducted from a sample of 100 numbers by questioning whether negative marking improves the quality of products. 44 people, which is $88 \%$ responded that negative marking improves the quality of the product and only 6 people, that is $12 \%$ responded negative marking is not making any change in the quality of the product. From the survey it is very clear that, negative marking improves the quality of products, which means, negative marking makes sellers to improve the quality of products they are selling. Because of the negative marking, sellers are worried about their selling restrictions; they are trying to satisfy the customers with the required quality.

\section{Feedback that causes negative marking}

Online portals give negative marking to sellers for various reasons. Online sale is a marketing technique that involves customer interaction through online and there is no direct customer interaction. Hence it requires more number of checking procedures for validating the seller. There are different types of feedback received from the customers. All those feedbacks are taken into consideration and negative marking is provided when a seller sends a defective product, or fails to deliver the product on the due date.

There are different types of feedbacks given by the customers. It is

$$
\begin{array}{ll}
\multicolumn{2}{c}{\text { segregated in to }} \\
\text { 1. } & \text { Positive } \\
\text { 2. Negative } \\
\text { 3. Neutral }
\end{array}
$$

\begin{tabular}{|c|c|c|c|c|}
\hline & & 1 month & 6 months & 12 months \\
\hline$\oplus$ & Positive & 25 & 94 & 214 \\
\hline ( & Neutral & 10 & 54 & 107 \\
\hline$\Theta$ & Negative & 2 & 8 & 14 \\
\hline
\end{tabular}

Feedback ratings for last 12 months

Figure 1: Example feedback rating in online portal

\subsection{Positive feedback}

Positive feedback is the feedback given by the customer when a customer satisfied with the product received. He is happy with the product and makes a positive comment on the product, it includes different types of positive comments such as product received is in good condition and it was in line with the product specification provided by the seller.

\subsection{Negative feedback}

When a customer does not receive the product, or receive a defective product, then customer tries to mention that in feedback, it is a problem, because, customer paid the money and does not receive the product in good condition. It is not good for the online sales portal. Customer tries to avoid that portal when not satisfied. Hence it directly affects the sales in the online portal.

\subsection{Neutral feedback}

When a customer does not want to make any positive or negative comment and mentions that, product was received, it is a neutral comment. It does not make any impact on the seller, and hence no positive or negative marking will be given to the seller. It does not affect the sales in the online portal. It requires improvement to get a positive comment

\section{Claims by customers that cause negative marking}

Customers try to claim the money paid due to two different types of reasons.

1. Not receiving the item.

2. Significant changes and item not as described

\subsection{Not receiving the item}

In online portals, all sellers need to ensure the delivery of the product to the buyers in the stipulated time line.

Buyer can raise the claim for not receiving the item. It affects the seller performance. When the item is not received by the buyer within the stipulated time, buyer can raise the claim for not receiving the item.

When a buyer raises the claim for not receiving the item, then, investigation by online portal reveals that, fault is on seller side. Then it negative impact on the seller performance evaluation and it is considered as a bad transaction. 


\subsection{Significant changes and item not as described}

Buyer can raise a claim when there are significant changes in the item, and it is not as described, then it can be considered for replacement or refund to the buyer. It is also called guarantee policy in the online portals. When a buyer says that it is not as described, then it makes a negative impact in the evaluation for seller performance. Sellers need to maintain the timeline for the delivery of the product. There are system initiated claims and refund procedures, that eases the buyers to raise the claim without any hassles. Such kind of incidents makes negative marking on seller performance evaluation. Seller has all rights to cancel a transaction and refund money to the buyer. Seller cannot provide false details regarding shipment of the product, then, online portals take appropriate action against the sellers. It can be restriction of the number of items a seller can sell or restriction for posting a new product for sale, or some other similar restriction, or limitation in seller privileges, and even account can be suspended.

Table 2: Comparison of Online Portal with and Without Negative Marking

\begin{tabular}{|c|c|c|}
\hline \multicolumn{3}{|c|}{$\begin{array}{l}\text { Whether Issue Resolved (Item not received, Significant changes and } \\
\text { item not as described)? }\end{array}$} \\
\hline Online portal type & $\begin{array}{l}\text { Item not received } \\
\text { (Issue Resolved) }\end{array}$ & $\begin{array}{c}\text { Significant changes and item } \\
\text { not as described (Issue } \\
\text { Resolved) }\end{array}$ \\
\hline $\begin{array}{l}\text { Online portal with } \\
\text { Negative marking }\end{array}$ & 49 & 44 \\
\hline $\begin{array}{l}\text { Online portal } \\
\text { without Negative } \\
\text { marking }\end{array}$ & 37 & 40 \\
\hline
\end{tabular}

A detailed survey is carried out with questions, whether the issues of i) Item not received, ii) Significant changes and item not as described were resolved or not?. 50 Samples were considered for the survey and people were selected from different variety of the people required for the study. It is observed that 49 people replied that item not received is resolved. That means, $98 \%$ people received the item after raising the issue. It is only 37 people out of 50 replied item not received is resolved. That means only $74 \%$ resolved after raising the issue. When it comes for the question of whether item not as described, 44 people replied that, issue raised for item not as described, is resolved because of negative marking. It is $88 \%$. For online portal without negative marking, it is 40 and $80 \%$. From this survey it is very clear that, negative marking makes a very good effect on resolving the issues of item not received and item not as described.

\section{Performance evaluation calculation}

Performance calculation is a procedure followed in online portals to give positive feedback percentage for sellers, which help in distinguishing the good sellers and bad sellers. Performance calculation procedures in different online portals are explained here.

\subsection{E-BAY}

Performance calculation in eBay is based on 12 months feedback from the customers, total number of positive and negative feedback is used for evaluating the performance, repeated feedback for the same purchase in the same calendar year is excluded, and not considered for evaluation.

Calculation Formula in e Bay is as follows,

Positives / (Positives + Negatives)

Example:

Total number of positive and negative feedback in past 12 months,

Positives: 50

Negatives: 8

Then, this member's positive feedback percentage is given by the formula,

$$
50 /(50+8)=86 \%
$$

\subsection{Amazon}

Seller performance evaluation is the procedure in Amazon follows the procedure of calculating the performance as mentioned below. Defect Order rate: $<1 \%$

Cancel rate because of Pre-fulfillment: $<2.5 \%$

Time delay in shipment rate: $<4 \%$

When the buyer fails to meet these targets, then online portals may remove the seller privileges.

\subsection{Flipkart}

Flipkart follows the procedure mentioned below to calculate the seller performance.

Defect Rate Order measure $=[$ Total number of claims, customer cancellation or negative feedback] (Lagging in the orders made in the past 3 months)

Seller with good performance $=$ having a low Defect Rate Order $(<1 \%)$ and with zero negative feedbacks, and no claims.

\section{Actions By online portals for negative marking}

1. Seller needs to provide proper answer to the online portal to the customer feedback.

2. Sellers are restricted to sell less number of products till negative marking is changed into neutral or positive.

3. Seller does not receive money when a customer claims a guarantee for defective product of item not received.

4. Sellers are completely blocked, suspension of account, cannot able to sell the products in that online portal.

5. Sellers need to pay fine for inconvenience caused to the customer.

\section{Conclusion}

Negative marking makes a good effect on improvement of sales in online portals. It improves the customer satisfaction. Guarantee for money back is an advantage for the customers. That is what most of the customers expect. Because when they purchase a product and not satisfied with that, try to claim for return of money paid. Negative marking improves the seller performance, and customers become happy and try to use that online portal again and again. Hence it increases the overall performance of sales in online portal. Internet became an inevitable marketing source for business. Several steps were taken by the online portals to maintain the customer satisfaction. Negative marking makes a good impact on customer satisfaction.

Thus, negative marking is an important marketing decision making phenomenon. It helps to sustain the existing customers and to increase the new customers. This is very well outlined in this journal.

\section{Future Research Scope}

Negative marking in online portals was analyzed in this journal. There are so many factors that affect the negative marking in online portals. How to improve the positive percentage score in online marketing is an important topic that can be discussed in future. Seller perspective of negative marking is also a kind of study that can help to understand the usage of negative marking. Hence there is a good scope for future studies for negative marking in online marketing management decisions. 


\section{References}

[1] Shanteau J, "Management decision making", Encyclopedia of Psychology and Behavioral Science, (2001), pp.913-915.

[2] Jonathan B, "Normative models of judgment and decision making", Blackwell Handbook of judgment making, (2004), pp.19-36.

[3] Jospesh A, "Victoria Campbell \& Piers Steel", Decision making for sustainability, A systematic review of the body of knowledge Network of Business Sustainability, (2012).

[4] Michael R, "Consumer Decision-Making Models, Strategies, and Theories", Decision, Analyst, (2005).

[5] Lunenburg FC, "Decision making in organizations", International journal of management, business, and administration, Vol.15, No.1, (2011), pp.1-9.

[6] Simon H.A, The new science of management decision, Prentice Hall, N.J, (1960).

[7] Edwards W, "The theory of decision making", Psychological Bulletin, (1954), pp.380-417.

[8] Hawes J, "Managerial decision making", Journal of Small Business Management, Vol.15, (1977)

[9] Shanteu J, Mellers BA \& Schum DA, Decision Science and technology: Reflections on the contributions of Ward Edwards. Kulwer Academic publishers, Norwell, (1999).

[10] Ken Corley J, Zack J \& Rhea Ingram W, Internet marketing, a content analysis of the research, Institute of Information Management, University of St. Gallen, Switzerland, (2013).

[11] Mickey K \& Sharon D. Retailing and E-tailing, Goodheart Willcox Publishers, USA, (2015).

[12] Dawn DSK \& Kar U, "E-Tailing in India: Its issues, opportunities and effective strategies for growth and development", International Journal of Multidisciplinary Research, Vol.1, No.3, (2011), pp.101-115.

[13] Nasr L, Burton J, Gruber T \& Kitshoff J, "Exploring the impact of customer feedback on the well-being of service entities: A TSR perspective", Journal of Service Management, Vol.25, No.4, (2014), pp.531-555.

[14] Kotler P, Marketing Management. 5th Edition, Pearson Education, Inc., London, (2003)

[15] Ozuru HN \& Kalu SE, An Introduction to Electronic Marketing Cutting Edge, Port Harcourt, (2006).

[16] Anderson RE, "Consumer dissatisfaction: The effect of disconfirmed expectancy on perceived product performance", Journal of marketing research, (1973), pp.38-44.

[17] Lvovs A \& Mutule A, "Customer Dissatisfaction Index and Its Improvement Costs", Scientific Journal of Riga Technical University. Power and Electrical Engineering, Vol.26, No.1, (2010), pp.21-26.

[18] Gyasi S, "Customer dissatisfaction and complaining responses towards mobile telephony services", The African Journal of Information Systems, Vol.4, No.3, (2012), pp.83-99.

[19] Chinna SRP \& Ventakesh R, "E-tailing in India: Its growth, issues, opportunities and development", IJARIIE, (2016), pp.185-194.

[20] Nwokah NG \& Ngirika D, "Online Advertising and Customer Satisfaction of E-Tailing Firms in Nigeria”, Intelligent Information Management, Vol.10, No.1, (2017), pp.1-16.

[21] Doherty NF \& Ellis-Chadwick F, "Internet retailing: the past, the present and the future", International Journal of Retail \& Distribution Management, Vol.38, no.11/12, (2010), pp.943-965.

[22] e Bay, California, USA, accessed 21 Jan 2018, www.ebay.com, 1995.

[23] Flipkart, Bangaluru, India, accessed 21 Jan 2018, www.flipkart.com, 2007.

[24] Amazon, Washington, USA, accessed 21 Jan 2018, www.amazon.com, 1994. 